\title{
THE DEVELOPMENT OF MOTION GRAPHIC AS EDUCATION MATERIAL FOR PROMOTING ADEQUATE HOME DRUG STORAGE
}

\author{
Nanda Puspita ${ }^{1)}$, Wardiyah ${ }^{1)}$ \\ ${ }^{1}$ Jurusan Farmasi Politeknik Kesehatan Jakarta II \\ Jl.Percetakan negara no.23 Jakarta Pusat \\ E-mail: nandapuspita28@gmail.com
}

Submited : 10 November 2019 ; Accepted : 20 November 2019

https://doi.org/10.36525/sanitas.2019.10

\begin{abstract}
Inappropriate drug storage at home is a common health problem in the community. Improper storage of drug may affect the quality of drug. Pharmacist, as a drug informer, plays important role providing education about how to store medicines. This study aims to develop educational media in the form of motion graphics and analyze the effect of media to improve the knowledge of drug storage in housewives. The research was conducted in three stages; media development, content revision, and media testing. The media was developed with drug storage material compiled by two experts. Then the content, appearance and duration are evaluated. To find out the influence of the media in increasing knowledge about drug storage, quasi experimental was applied with a one group pretest-posttest design in October 2019 for 28 housewives. From the results of snowball sampling, it is known that the average age of respondents was 43 years, with a range of 18-58 years and the majority were high school graduates (67.9\%). Knowledge of respondents was assessed using a knowledge questionnaire. The motion graphic media has a significant influence on increasing the knowledge of housewives regarding the correct storage of drugs. This is indicated by a significant difference in the pretest (67.85) and posttest scores (83.67) after watching 3 minute motion graphic shows $(\mathrm{p}=0.001, \mathrm{Cl} 95 \%)$.
\end{abstract}

Keywords: health education, home drug storage, motion graphic

This is an open access journal, and articles are distributed under the terms of the Creative Commons Attribution-NonCommercial-ShareAlike 4.0 License, which allows others to remix, tweak, and build upon the work non-commercially, as long as appropriate credit is given and the new creations are licensed under the identical terms.

C2019 Sanitas

\section{ABSTRAK \\ PENGEMBANGAN MEDIA MOTION GRAPHIC SEBAGAI MATERI EDUKASI PENYIMPANAN OBAT YANG BENAR DI RUMAH TANGGA}

Penyimpanan obat di rumah masih menjadi permasalahan kesehatan di masyarakat. Penyimpanan obat yang tidak tepat dapat mempengaruhi kualitas obat yang digunakan. Oleh karena itu, apoteker sebagai drug informer berperan memberikan edukasi tentang penyimpanan obat yang benar. Penelitian ini bertujuan untuk mengembangkan media edukasi berupa motion graphic dan menganalisis pengaruh pemberian media terhadap pengetahuan penyimpanan obat pada ibu rumah tangga. Penelitian dilakukan dalam tiga tahap, yaitu pengembangan media, revisi isi, dan pengujian. Media dikembangkan dengan materi penyimpanan obat yang disusun oleh dua orang panel ekspert. Selanjutnya dilakukan evaluasi terhadap isi, tampilan, dan durasi. Untuk mengetahui pengaruh media dalam peningkatan pengetahuan tentang penyimpanan obat, eksperimental 
SANITAS: JURNAL TEKNOLOGI DAN SENI KESEHATAN

ISSN : 1978-8843 (PRINT) /2615-8647 (ONLINE)

VOL.10 (2), 2019 : 92 - 101

kuasi diterapkan dengan one group pretest-posttest design di bulan Oktober 2019 pada 28 orang ibu rumah tangga. Dari hasil snowball sampling, diketahui rerata usia responden adalah 43 tahun, dengan rentang 18-58 tahun dan mayoritas berpendidikan SMA (67,9\%). Pengetahuan responden dinilai menggunakan kuesioner pengetahuan sesuai isi media. Media motion graphic memberi pengaruh signifikan terhadap peningkatan pengetahuan ibu rumah tangga terkait penyimpanan obat yang benar. Hal ini ditunjukkan dengan perbedaan bermakna pada skor pretest $(67,85)$ dan posttest $(83,67)$ setelah menonton tayangan motion graphic berdurasi 3 menit $(\mathrm{p}=0,001, \mathrm{Cl} 95 \%)$.

Kata Kunci: edukasi kesehatan, penyimpanan obat, motion graphic

\section{PENDAHULUAN}

Penyimpanan obat di lingkungan masyarakat, khususnya dalam satuan rumah tangga, apabila tidak diikuti dengan pengetahuan yang benar tentang obat akan memicu timbulnya penggunaan yang tidak rasional serta cara penyimpanan yang tidak tepat. Survei di beberapa negara khususnya negera berkembang, menunjukkan adanya ketidaktepatan penyimpanan obat, diantaranya penyimpanan item antibiotik dan obat ethical tanpa resep dokter $(1,2,3)$, serta penyimpanan di lokasi yang kurang memadai.(4,5) Di samping itu, studi lain juga menyebutkan pentingnya menyimpan obat rumah tangga yang jauh dari jangkauan anak-anak.(6)

Di Indonesia, masih banyak kasus penyimpanan obat yang tidak tepat di rumah tangga. salah satu survei terhadap 300 warga di wilayah Jatinegara, Jakarta Timur mengungkapkan persentase penyimpanan obat sisa yang tidak digunakan mencapai $22,21 \%$ dan $5 \%$ diantaranya tidak dapat diidentifikasi karena telah terlepas dari kemasan primernya.(7) Berbagai permasalahan penyimpanan obat di rumah tangga membutuhkan penanganan yang berkesinambungan, dimulai dengan melakukan edukasi pada masyarakat.

Pemerintah dan Ikatan Apoteker Indonesia (IAI) telah berupaya mengedukasi masyarakat terkait obat dengan membentuk program DAGUSIBU (Dapatkan, Gunakan, Simpan, dan Buang Obat dengan Benar) untuk mewujudkan pengelolaan obat yang baik di lingkungan rumah tangga. Program yang tercakup dalam kampanye Gerakan Keluarga Sadar Obat (GKSO) ini merupakan upaya meningkatkan kesadaran masyarakat dan sekaligus mencerdaskan masyarakat dalam berperilaku sehat, khususnya terkait dengan obat. Secara nasional gerakan ini juga menjadi gerakan yang pertama kali dilakukan oleh profesi apoteker di Indonesia.(8) 
SANITAS: JURNAL TEKNOLOGI DAN SENI KESEHATAN ISSN : 1978-8843 (PRINT) /2615-8647 (ONLINE)

Hingga saat ini, program edukasi DAGUSIBU mayoritas dilakukan dengan media konvensional cetak seperti poster dan leaflet. Kegiatan edukasi kesehatan dengan menggunakan media gambar menjadi sarana yang efektif dalam menjangkau masyarakat. Beberapa studi menunjukkan bahwa adanya panduan bergambar mampu meningkatkan pemahaman pasien tentang instruksi perawatan penyakit (9) serta pengelolaan penyakit kronis.(10) Adanya perpaduan gambar dan teks mampu meningkatkan daya ingat pasien terhadap materi yang disampaikan, menambah kepercayaan diri untuk menggunakan obat dan mengambil keputusan terkait penyakitnya.(11)

Dengan berkembangnya teknologi dan kemajuan internet, saat ini semakin bertambah program edukasi kesehatan masyarakat yang disebarkan dalam bentuk multimedia, menggunakan perpaduan antara gambar, teks, suara, dan gerak. Menurut Asosiasi Penyelenggara Jasa Internet Indonesia (APJII), pemanfaatan internet untuk mencari informasi kesehatan di Indonesia mencapai 51,06\%. Besarnya penetrasi pengguna internet di Indonesia (54,68\% dari seluruh penduduk di tahun 2017)(12) dapat menjadi peluang penyebaran edukasi kesehatan yang efektif. Penelitian ini bertujuan untuk mengembangkan media edukasi penyimpanan obat berbentuk motion graphic dan menganalisa efektifitasnya dalam meningkatkan pengetahuan ibu rumah tangga.

\section{METODE PENELITIAN}

\section{Produksi Media Motion Graphic}

Tahap produksi motion graphic tentang edukasi penyimpanan obat dilakukan oleh dua peneliti dengan mengkonsep isi dan tata letak gambar ke dalam storyboard. Materi penyimpanan obat diadaptasi dari materi Gerakan Masyarakat Cerdas Menggunakan Obat (Gema Cermat) Kementerian Kesehatan RI(13) dan sumber literatur lain yang relevan.(14) Isi materi mencakup cara penyimpanan sediaan obat padat, semipadat, dan cair, himbauan untuk menjauhkan obat dari anak-anak, lokasi dan suhu penyimpanan yang tetap, serta cara penyimpanan obat-obat khusus (insulin dan suppositoria). Konten/isi dibuat dengan bahasa yang mudah dimengerti oleh orang dewasa umum (Gunning Fox Score $(15)=16,6)$. Setelah 
SANITAS: JURNAL TEKNOLOGI DAN SENI KESEHATAN

itu, teks dan gambar dipadukan dengan suara untuk divisualisasikan dengan bantuan pihak desainer animasi. Hasil visualisasi motion graphic tampak pada gambar 1.
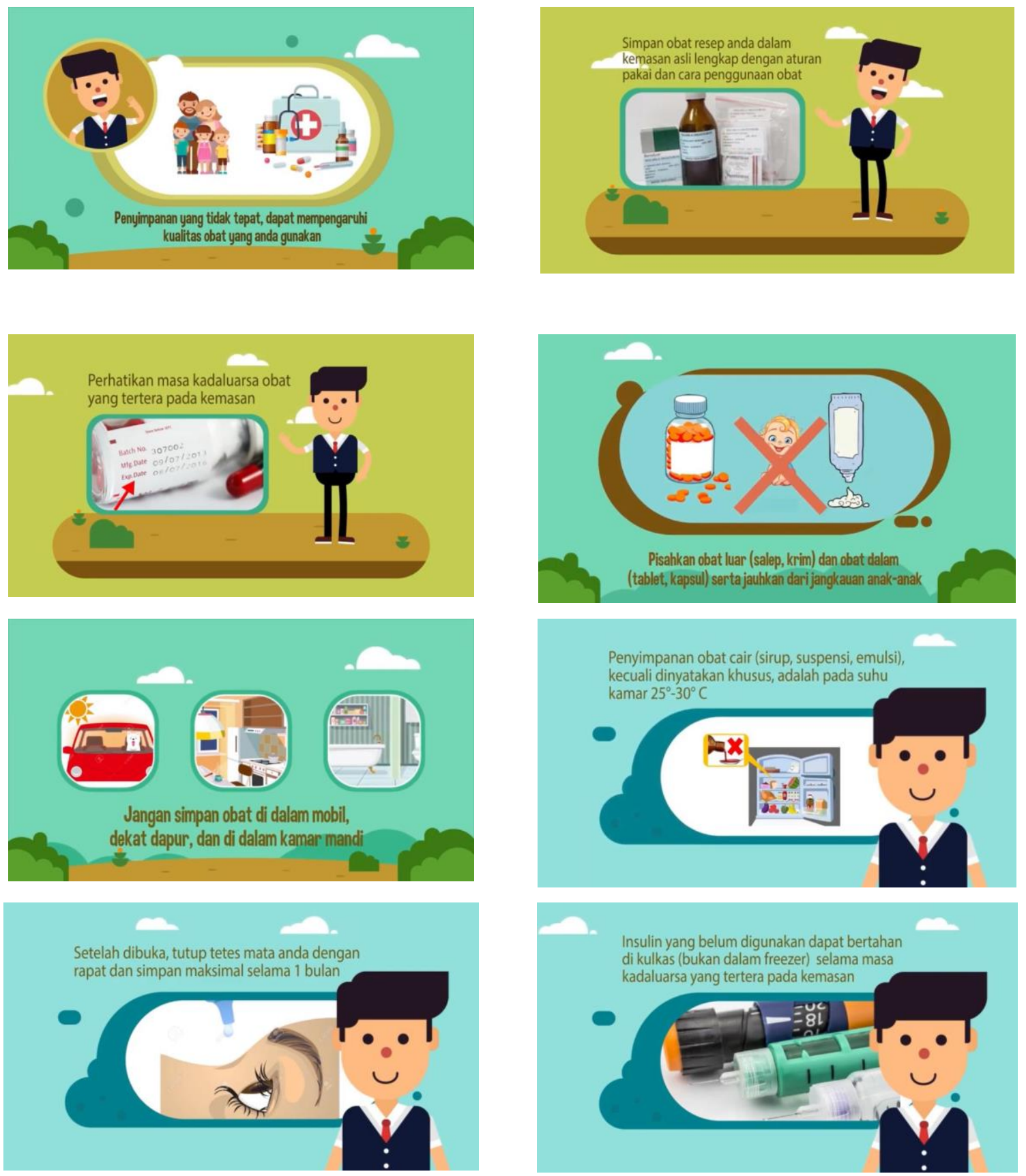

Gambar 1 Tampilan motion graphic berjudul 'Cara Penyimpanan Obat yang Benar'; ki-ka, atas ke bawah -- $\rightarrow$ 0:11: pengaruh penyimpanan terhadap kualitas obat; 0:29: anjuran menyimpan obat resep pada kemasan asli; 0:41: anjuran untuk memperhatikan tanggal kadaluarsa; 0:57: himbauan menjaga obat dari jangkauan anak; 1:09: larangan menyimpan obat di tempat bersuhu labil; 1:23: larangan menyimpan obat sirup di kulkas (kecuali sirup 
SANITAS: JURNAL TEKNOLOGI DAN SENI KESEHATAN

antibiotik); 1:58: jangka waktu penyimpanan tetes mata, 2:08: penyimpanan sediaan insulin yang tepat

\section{Analisa Media Motion Graphic}

Kualitas dan efektifitas media motion graphic diujikan terhadap responden dengan kriteria inklusi ibu rumah tangga, usia minimal 18 tahun, dan pernah mengakses media sosial. Responden diminta menjawab pretest terkait penyimpanan obat, kemudian menonton tayangan motion graphic, dan terakhir menjawab soal posttest. Hasil skor pengetahuan dianalisa dengan uji T-berpasangan (paired T-test).

\section{HASIL DAN PEMBAHASAN}

Penelitian berbasis promosi kesehatan telah banyak dilakukan, tetapi penelitian promosi kesehatan terkait edukasi obat masih jarang dilakukan. Farmasis sebagai drug informer memiliki peran dalam masyarakat untuk memberikan edukasi terkait obat, termasuk cara penggunaan dan penyimpanannya. Di Era digital dan penetrasi internet dalam kehidupan sehari-hari, edukasi tentang obat semakin banyak diberikan melalui media sosial dengan bantuan video/gambar bergerak. Penelitian ini bertujuan untuk mengembangkan media edukasi berbentuk motion graphic dan menganalisis baik secara kualitatif maupun kuantitatif pengaruh pemberian edukasi tersebut dalam meningkatkan pengetahuan penyimpanan obat.

Tabel 1 Karakteristik Demografi Ibu Rumah Tangga sebagai Responden Penelitian

\begin{tabular}{cll}
\hline No. & \multicolumn{1}{c}{ Karaktek Demografi } & \multicolumn{1}{c}{ Keterangan } \\
\hline 1. & Usia & 43 tahun $( \pm 11,2)$ \\
& Rerata $( \pm$ SD) & 18 tahun \\
& Minimum & 58 tahun \\
& Maksimum & 3 \\
& $<$ 26 tahun & 4 \\
& 26-35 tahun & 8 \\
& 36-45 tahun & 13 \\
26 tahun ke atas & Tingkat Pendidikan & $3(10,7 \%)$ \\
& Rendah (SD, SMP) & $19(67,9 \%)$ \\
& Menengah (SMA) & $6(21,4 \%)$ \\
& Tinggi (D3, S1, dst) & \\
\hline
\end{tabular}


SANITAS: JURNAL TEKNOLOGI DAN SENI KESEHATAN ISSN : 1978-8843 (PRINT) /2615-8647 (ONLINE)

Pengujian terhadap media motion graphic dilakukan di wilayah kelurahan Johar Baru, lokasi yang dekat dengan institusi peneliti. Berdasarkan karakteristik responden $(\mathrm{n}=28)$, keseluruhannya adalah ibu rumah tangga dengan usia termuda 18 tahun dan tertua 58 tahun. Lebih dari separuh sampel memiliki tingkat pendidikan menengah/SMA sederajat $(\mathrm{n}=19 ; 67,9 \%)$, data selengkapnya terdapat pada tabel berikut.

Pada tahap pertama, responden diberi pretest yang berisi 7 pertanyaan terkait isi video motion graphic untuk mengetahui wawasan dasar (baseline) tentang penyimpanan obat. Kemudian responden dipersilakan untuk menyaksikan tayangan motion graphic tentang cara penyimpanan obat yang berdurasi 3 menit. Mayoritas responden memberi tanggapan positif terkait cara penyampaian informasi yang tertuang dalam video. Beberapa diantara responden mengemukakan bahwa larangan penyimpanan obat di mobil adalah hal baru bagi mereka. Suhu yang tinggi di dalam mobil (dapat mencapai $40^{\circ} \mathrm{C}$ ) dapat mempengaruhi efikasi obat.(16) Disamping itu, responden juga baru mengetahui informasi tentang jangka waktu penyimpanan obat tetes mata multidose yaitu 1 bulan. Selama ini mereka mengaku menyimpan sediaan tersebut dalam waktu yang lebih lama.

Setelah dilakukan posttest, terdapat peningkatan pengetahuan yang signifikan $(\mathrm{p}=0,001)$ sebelum dan sesudah intervensi. Keterangan selengkapnya terdapat pada tabel di bawah ini.

Tabel 2 Pengaruh Menonton Motion Graphic terhadap Pengetahuan Penyimpanan Obat Ibu Rumah Tangga di Kelurahan Johar Baru

\begin{tabular}{llccc}
\hline No. & $\begin{array}{l}\text { Pemberian Motion } \\
\text { Graphic }\end{array}$ & N & $\begin{array}{c}\text { Rata-rata skor pengetahuan } \\
( \pm \mathrm{SD})\end{array}$ & $p$-value \\
\hline 1 & Sebelum perlakuan & 28 & $67,85( \pm 18,9)$ & $0,001^{*}$ \\
& Setelah perlakuan & & $83,67( \pm 15,4)$ & \\
& & & & \\
\hline
\end{tabular}

*uji T-berpasangan (paired t-test), $\alpha=5 \%$

Motion graphic merupakan media audio-visual yang saat ini sering digunakan untuk menyampaikan informasi, termasuk dalam hal promosi kesehatan. Metode ini merupakan langkah baru yang berpotensi mendorong perilaku sehat pada semua kalangan masyarakat. Seperti yang dikemukakan oleh Notoatmodjo (17), promosi kesehatan bertujuan jangka panjang untuk menciptakan perilaku yang kondusif dalam menjaga kesehatan. Video 
SANITAS: JURNAL TEKNOLOGI DAN SENI KESEHATAN ISSN : 1978-8843 (PRINT) /2615-8647 (ONLINE)

VOL.10 (2), 2019 : 92 - 101

motion graphic dalam penelitian ini bertujuan agar masyarakat menyadari pentingnya cara menjaga kesehatan dengan langkah penyimpanan obat yang benar.

Kemampuan masyarakat menyerap informasi kesehatan berhubungan dengan tingkat kesadaran masyarakat tentang kesehatan, atau disebut dengan melek kesehatan (health literacy).(17) Tingkat health literacy dipengaruhi oleh beberapa faktor, salah satunya adalah tingkat pendidikan. Penyampaian edukasi kesehatan perlu memperhatikan health literacy pada kelompok sasaran. Modifikasi teknologi dengan penambahan gambar dan video meningkatkan pemahaman tentang edukasi kesehatan pada populasi dengan health literacy yang rendah.(18) Sebuah studi lain menunjukkan, pemberian informasi kesehatan dengan bantuan gambar kartun dapat meningkatkan kepuasan dan pemahaman pasien terhadap instruksi perawatan luka, khususnya bagi masyarakat berpendidikan menengah ke bawah.(9) Dengan adanya akses internet dan maraknya penggunaan sosial media, video motion graphic dapat menjadi alternatif promosi kesehatan yang cost-effective untuk semua kalangan masyarakat. Studi di London menyatakan penggunaan video edukasi tentang penyakit jantung coroner (PJK) dapat menjembatani kesenjangan informasi terkait penyakit tersebut pada populasi imigran. Sejumlah 18 responden wanita keturunan Bangladesh mendapat manfaat signifikan dari intervensi penelitian dan berkeinginan mengubah gaya hidup lebih sehat setelah menonton video edukasi.(19)

Pada penelitian ini terdapat beberapa keterbatasan. Pertama, penelitian ini hanya mengukur daya ingat/recall jangka pendek dengan memberikan instrument kuesioner sesaat setelah intervensi. Penelitian ini belum sampai mengukur perilaku responden dalam menyimpan obat pasca intervensi. Kedua, responden dalam penelitian tidak dipilih secara acak. Teknik snowball sampling dalam penelitian ini mungkin menyebabkan salah satu faktor predisposisi seperti lingkungan sosial responden ikut mempengaruhi respon terhadap pertanyaan kuesioner. Ketiga, adanya tipe pertanyaan yang sama antara pretest dan posttest dapat menimbulkan kecenderungan responden hanya fokus pada konten media yang berkaitan dengan pertanyaan. Diperlukan penelitian lanjutan yang mencakup sampel lebih besar dan durasi yang lebih panjang untuk melihat efektifitas pemberian edukasi penyimpanan obat melalui media motion graphic. Selain itu, perlu adanya uji pembanding 
SANITAS: JURNAL TEKNOLOGI DAN SENI KESEHATAN

dengan media edukasi konvensional (leaflet/booklet) untuk melihat ada tidaknya perbedaan pengaruh dengan motion graphic dalam peningkatan pengetahuan penyimpanan obat.

\section{SIMPULAN}

Media motion graphic yang diproduksi sebagai media edukasi kesehatan mengandung konten dengan bahasa yang mudah dimengerti (Gunning Fox Score $=16,6$ ). Keseluruhan isi, tampilan dan durasi mendapat penilaian baik dari responden. Analisis skor pengetahuan setelah paparan media menunjukkan adanya perbedaan yang bermakna $(\mathrm{p}=0,001)$. Penelitian selanjutnya diperlukan untuk membandingkan efektivitas media motion graphic dengan media konvensional (cetak) dalam mempengaruhi pengetahuan penyimpanan obat yang benar di kalangan masyarakat, khususnya ibu rumah tangga.

\section{UCAPAN TERIMA KASIH}

Penelitian ini terlaksana berkat bantuan dana dari program risbinakes untuk calon dosen pemula. Ucapan terimakasih kepada direktur Politeknik Kesehatan Jakarta II, bapak Joko Sulistiyo, M.Si atas bimbingannya serta bapak \& ibu di bagian Penelitian dan Pengembangan Politeknik Kesehatan Jakarta II yang memberi saran berarti untuk perbaikan penelitian.

\section{DAFTAR PUSTAKA}

1. De Bolle L, Mehuys E, Adriaens E, Remon JP, Van Bortel L, Christiaens T. Home medication cabinets and self-medication: A source of potential health threats? Ann Pharmacother. 2008. doi:10.1345/aph.1K533

2. Ocan M, Bbosa GS, Waako P, Ogwal-Okeng J, Obua C. Factors predicting home storage of medicines in Northern Uganda. BMC Public Health. 2014. doi:10.1186/1471-2458-14-650

3. Jassim A-M. In-home Drug Storage and Self-medication with Antimicrobial Drugs in Basrah, Iraq. Oman Med J. 2010;25(2). doi:10.5001/omj.2010.25

4. Tsiligianni IG, Delgatty C, Alegakis A, Lionis C. A household survey on the extent of home medication storage. A cross-sectional study from rural Crete, Greece. 
SANITAS: JURNAL TEKNOLOGI DAN SENI KESEHATAN

doi:10.3109/13814788.2011.604674

5. Gracia-Vásquez SL, Ramírez-Lara E, Camacho-Mora IA, et al. An analysis of unused and expired medications in Mexican households. Int J Clin Pharm. 2015;37(1):121-126. doi:10.1007/s11096-014-0048-1

6. Randall Martins RI, Duarte Farias AI, Monique da Costa Oliveira YI, dos Santos Diniz RI, Gouveia Oliveira AI, Randall Martins Av General Gustavo Cordeiro de Farias R. Prevalence and risk factors of inadequate medicine home storage: a community-based study. Artig Orig Rev Saude Publica. 2017;51. doi:10.11606/S1518-8787.2017051000053

7. Yunus Y, Puspita N, Fajri P. The Extent of Inadequate Drug Storage: A Household Survey in Jatinegara, East Jakarta. Asian J Appl Sci. 2018;6(6). doi:10.24203/AJAS.V6I6.5556

8. Pedoman Pelaksanaan Gerakan Keluarga Sadar Obat (GKSO). Ikatan Apoteker Indonesia. http://iaisumbar.net/site/wp-content/uploads/2014/09/GKSO-PedomanPelaksanaan.pdf. Published 2014.

9. Delp C, Jones J. Communicating Information to Patients: The Use of Cartoon Illustrations to Improve Comprehension of Instructions. Acad Emerg Med. 1996;3(3):264-270. doi:10.1111/j.1553-2712.1996.tb03431.x

10. Hilman Agrimon O, Street J. Developing Comprehensive Diabetes Education Materials for Structured Patient Education Programs in Primary Care Setting. Int $J$ Public Heal Sci. 2016;5(1):16. doi:10.11591/ijphs.v5i1.4758

11. van Beusekom MM, Grootens-Wiegers P, Bos MJW, Guchelaar H-J, van den Broek JM. Low literacy and written drug information: information-seeking, leaflet evaluation and preferences, and roles for images. Int J Clin Pharm. 2016;38(6):13721379. doi:10.1007/s11096-016-0376-4

12. Infografis: Penetrasi dan Perilaku Pengguna Internet Indonesia tahun 2017. Asosiasi Penyelenggara Jasa Internet Indonesia (APJII). www.teknopreneur.com. Published 2017.

13. Materi Promosi Gema Cermat. Direktorat Jenderal Kefarmasian dan Alat Kesehatan 
SANITAS: JURNAL TEKNOLOGI DAN SENI KESEHATAN

Kementerian Kesehatan RI. http://farmalkes.kemkes.go.id/2016/05/materi-promosigema-cermat-1-logo-banner-brosur-poster-dan-stiker/. Published 2016. Accessed November 10, 2019.

14. Guidance on the Expiry Dates and Storage of Medicine in care Homes (with or without nursing). NHS Herefordshire Clinical Commissioning Group. https://www.herefordshireccg.nhs.uk/library/publications-1/1075-guidance-onexpiry-dates-and-storage-of-medicines-in-care-homes/file. Published 2018. Accessed November 10, 2019.

15. Readability Test Results. https://www.webfx.com/tools/read-able/check.php. Accessed November 10, 2019.

16. Crichton B. Keep in a cool place: exposure of medicines to high temperatures in general practice during a British heatwave. J R Soc Med. 2004;97(7):328-329. doi:10.1258/jrsm.97.7.328

17. Notoatmodjo S. Pendidikan Dan Perilaku Kesehatan. 1st ed. Jakarta: PT.Rineka Cipta; 2003.

18. Yeung DL, Alvarez KS, Quinones ME, et al. Low-health literacy flashcards \&amp; mobile video reinforcement to improve medication adherence in patients on oral diabetes, heart failure, and hypertension medications. J Am Pharm Assoc. 2017;57(1):30-37. doi:10.1016/j.japh.2016.08.012

19. Latif S, Ahmed I, Amin MS, Syed I, Ahmede N. Exploring the potential impact of health promotion videos as a low cost intervention to reduce health inequalities: A pilot before and after study on Bangladeshis in Inner-city London. London J Prim Care (Abingdon). 2016;8(4):66-71. doi:10.1080/17571472.2016.1208382 